\title{
Systematic Review of Enjoyment Element in Health- Related Game-Based Learning
}

\author{
https://doi.org/10.3991/ijet.v15i21.17345
}

Habibah Ab Jalil ${ }^{(凶)}$, Nurul Amelina Nasharuddin, Erzam Marlisah, Ahmad Iqmer Nashriq Mohd Nazan, Ismi Arif Ismail, Aini Marina Ma'rof, Nur Ain Farhan Mohd Rusdi, Zeinab Zaremohzzabieh

Universiti Putra Malaysia, Serdang, Malaysia

habibahjalileupm.edu.my

\begin{abstract}
Educational games are often used as teaching and learning tools, with studies showing that game-based learning is widely accepted among children and teenagers. The experience of enjoyment typically associated with playing games sparks creativity, provides a deeper learning experience and allows the individual to connect various concepts, skills, and knowledge together. This paper builds upon previous studies on enjoyment in health-based gaming and aims to articulate a definition of enjoyment in gaming. Drawing on Miles' taxonomy, the review further sets out to identify and bridges gaps in our theoretical understanding of enjoyment. Three theories were found to be particularly relevant for explaining the concept of enjoyment concerning healthbased gaming: self-determination theory, flow theory, as well as uses and gratification theory.
\end{abstract}

Keywords-Enjoyment, Fun, Pleasure, Health Games, Health-Based Games, Serious Games, Theoretical Gaps

\section{Introduction}

With the ubiquity of digital technology and the subsequent proliferation of computer gaming, educational institutions have been under intense pressure to incorporate these innovations into the learning ecosystem [22]. "With the progression of ICT technology in recent years, an increasing number of games used in educational environments can also be used for high-level learning" [21, p.18]. Nonetheless, education providers have been challenged over how best to incorporate games in a pedagogically meaningful manner [59]. It is important, therefore, that we understand how learning takes place when playing games, and as such, we must focus on aspects of fun and enjoyment in learning [54].

Debate ranges regarding how best to gamify learning and development. This concept of gamification involves the use of games or game-like features in learning. Understanding gamification, however, also requires some clarification of the distinction between serious games and game-based learning. Moreover, researchers need to better define these terms to justify the data reviewed in this study, which is 
mostly related to serious games [19]. For reference, gamification is the inclusion of game elements or mechanics when applied to non-game activities to make them more compelling [13]. Gamification and serious games both attempt to solve a problem in terms of how to promote and motivate learning using game-based techniques and thinking [11].

Serious games are games that have been designed primarily for entertainment purposes [14]. Nevertheless, serious games are designed to challenge the player in some way, with these challenges impacting the player's physical or cognitive abilities, knowledge, attitudes, health, or mental wellbeing [11]. Game-based learning, on the other hand, is focused on defined learning outcomes, with gameplay elements simply a means to an end [51].

Various studies have been conducted to investigate the positive impact of serious games for health education $[15,45,47,65]$. Several scholarly attempts have also been mounted to identify the core features of serious games and how to improve their learning effectiveness $[13,15,47,54,59]$. Few of these studies, however, have attempted to reconcile learning outcomes in serious games with traditional learning theories. Having identified this gap in the theory, the present study aims to expand the body of knowledge surrounding health game-based learning through an investigation of the theory underpinning learning in gaming.

\section{$2 \quad$ Health Game-Based Learning}

Similar to game-based learning, health-based games incorporate health-related knowledge with defined learning outcomes [25]. Serious gaming and the gamification of health knowledge has the potential to reach a global audience and has been identified as a possible strategy for the health education professionals [24]. The main purpose of this study is to examine the concept of enjoyment to health-based games, which fall under the umbrella of serious games; therefore, this study includes any serious games with relevancy to health.

Health-based games are often used to improve the player's health knowledge and outcomes through a process of engaging distraction. Moreover, the repetitive nature of many video games is key to promoting the acquisition of procedural or behavioral health knowledge [48]. Consequently, health-based games have gained considerable attention in recent years as an alternative means to educate and train people $[15,16,47]$. Moreover, if these games are sufficiently enjoyable then they might also be commercially successful as serious games [5].

\section{$3 \quad$ Enjoyment in Game-Based Learning}

Not all games are created equal, with some games being more enjoyable than others. Games that lack enjoyment fail to engage the player or to promote learning [52]. The notion of learning through play is well established [3]. Children learn through social experiences and by simulating emotional consequences in the context 
of play [17]. Additionally, play provides children with a means with which to rehearse solutions to real-life problems, pressure, and desires [44].

Play and games seem to serve a myriad of functions, with players returning to a game even in the face of prior failure. These observations have led to some confusion among researchers to define the concept of enjoyment in gaming. Researchers from the fields of psychology and neuroscience use the term pleasure to describe enjoyment in general; communication researchers, on the other hand, define enjoyment in terms of one's positive reactions to media and its content $[18,63]$.

Enjoyment in gaming seems to be a composite concept made up of physiological, cognitive, and affective components [18]. Feelings of enjoyment occur once a balance has been struck between skill and challenge in the process of the player trying to accomplish the game's goal. This trade-off between skill and challenge is known as the flow state [9]. As such, enjoyment in a game is not only an intrinsically motivating activity for children, it also provides a way for them to construct different perceptions about their reality [44].

Concerning the education setting, game-based learning can only be successful if there is a willingness on the part of the player/learner to engage with the game and to be persistent. To this end, researchers have begun to identify various factors that influence enjoyment and learning, including interactivity [35], competition [60], and spatial presence and perceived reality [50]. Taking advantage of these factors, gamebased learning has become increasingly popular over recent years with the medium not only engaging individuals in quality learning experiences and but also their ability to consume player's attention $[34,58]$.

\section{Purpose of the Review}

This systematic review aims to conceptualize the notion of fun and enjoyment in games through an investigation of the various definitions in the literature to games which are used to enhance fun and enjoyment in teaching and learning. This paper begins with an overview of our systematic review methodology wherein we explore: (a) how fun and enjoyment are defined in health-based games, (b) what theoretical perspectives might be appropriate for different learning ecosystems, and (c) what key themes can be elucidated from the empirical results. With this in mind, this research is informed taxonomy of research gaps [42]. This taxonomy articulates seven research gaps, including gaps in the evidence, knowledge, practice-knowledge, methodology, empirical gaps, theoretical gaps, and population gaps. For this review, we have explored the subject of enjoyment in health-based gaming from the perspectives of theoretical and empirical gaps. Each of the findings from this analysis will be discussed separately, after which we offer proposals for future research directions of fun and enjoyment in health-based games. 


\section{$5 \quad$ Methods}

\subsection{Purpose}

A systematic review was conducted to identify the various definitions used throughout the literature to enjoyment in health-based games. Furthermore, this review aims to identify the theoretical gaps in the research literature. Consequently, the findings of this systematic review were categorized according to the taxonomy of research gaps [42].

\subsection{Search strategy}

The articles for systematic review were identified via a structured search strategy utilizing:

a) Electronic databases (i.e. IEEE Xplore, Emerald Insight, Science Direct, and EBSCO host)

b) Google Scholar

c) By following up on works cited in articles already identified

Most of the identified articles were retrieved from the online databases using the Boolean operator "OR" and the keywords enjoyment, fun, and pleasure; and Boolean operator "AND" followed by the keyword health games. Articles were searched until the point of saturation, whereby the same articles were being reported despite using different keyword combinations.

Figure 1 provides a diagrammatic representation of the literature search and review process. According to Figure 1, the initial search (without data parameters) resulted in the identification of 675 articles. To ensure that the search targeted studies related to the current use of games in health education, the time frame for the search was limited to the period from 2013 to 2018 . This narrowed the results down significantly and, after the application of the inclusion criteria (Table 1), resulting in the final inclusion of 16 articles for review. 


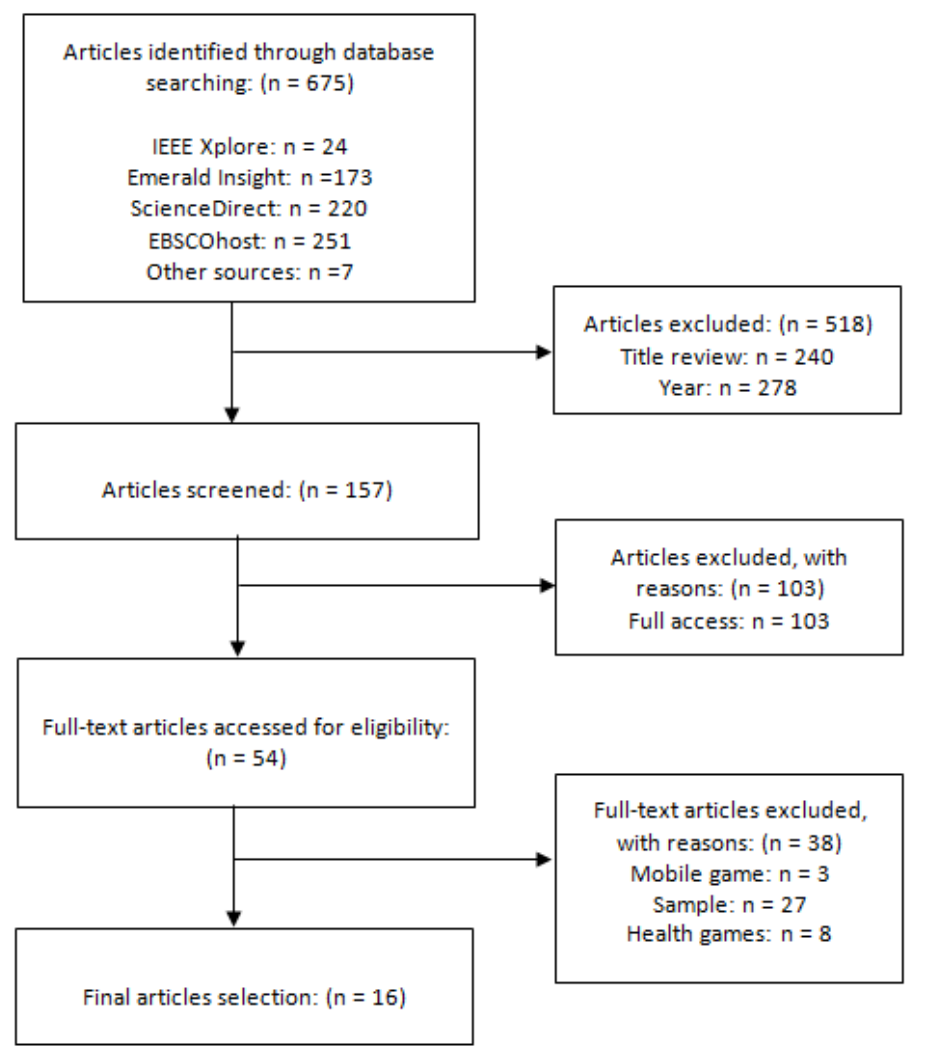

Fig. 1. Diagrammatic representation of the literature search and review process

\subsection{Inclusion and exclusion criteria}

Table 1 shows the inclusion and exclusion criteria for articles in this review. To be included in this systematic review, each study had to satisfy all inclusion and exclusion criteria.

Table 1. Inclusion and exclusion criteria.

\begin{tabular}{|c|c|}
\hline Inclusion criteria & Exclusion criteria \\
\hline $\begin{array}{l}\text { Enjoyment in health games } \\
\text { Fun in health games } \\
\text { Serious games } \\
\text { Games in the health context } \\
\text { Games used by young children and students (include } \\
\text { school and higher education institution) } \\
\text { The article is available to the public }\end{array}$ & $\begin{array}{l}\text { The games must not be for adult use } \\
\text { The games must not be for other than learning } \\
\text { purpose }\end{array}$ \\
\hline
\end{tabular}




\subsection{Data abstraction}

A table was constructed into which the following data were extracted from each article: author(s) last name, year, the title of the article, research objectives, underlying theory or theoretical framework, methodology, participants or sampling, and research findings.

\section{$6 \quad$ Results}

\subsection{Definition of enjoyment}

The concept of enjoyment in gaming has been a source of considerable scholarly attention over the past decade. According to the current systematic review, enjoyment has repeatedly been found to be an important element in mobile games. A broadly accepted definition of enjoyment in technology research alludes to enjoyment as the product of any computer-based activity that induces feelings of enjoyment as distinct from any other experience [12].

Table 2 shows that five studies $(n=5)$ defined enjoyment as a pleasure or positive feedback, two studies $(n=2)$ reported that different types of games were preferred by different genders, three studies $(n=3)$ reported that enjoyment was a function of the degree of freedom players experiences in a game, two studies $(n=2)$ highlighted the importance of prompt feedback on the experience of enjoyment, three studies $(n=3)$ found that enjoyment was based on the degree of complexity that a game presented to players, two studies $(n=2)$ found that enjoyment was related to ease-of-use, three studies $(n=3)$ found that enjoyment was a function of engagement, and two studies $(n=2)$ found that the experience of enjoyment was based on the computer user's attitudes.

Table 2. Literature review on related theory and definition of enjoyment.

\begin{tabular}{|l|l|}
\hline \multicolumn{1}{|c|}{ Theory } & \multicolumn{1}{|c|}{ Key Findings } \\
\hline $\begin{array}{l}\text { Self-determination theory, uses } \\
\text { and gratification theory, and flow } \\
\text { theory [3] }\end{array}$ & $\begin{array}{l}\text { Experience failure in playing games is an important element in game } \\
\text { enjoyment. The complexity and multifaceted nature of the concept of } \\
\text { engagement indicated that engagement can predict enjoyment. Past } \\
\text { studies have widely defined enjoyment as a pleasure response. The level } \\
\text { of enjoyment players get from a collaborative experience is dependent } \\
\text { on how they perceive their skills to collaborate with others in the group. } \\
\text { Attitude towards the use of technology. The satisfaction of competence, } \\
\text { relatedness, and autonomy. }\end{array}$ \\
\hline $\begin{array}{l}\text { Flow theory } \\
\text { and affect transfer theory [9] }\end{array}$ & $\begin{array}{l}\text { An experience of enjoyable and optimal time in which an individual } \\
\text { feels a sense of exhilaration, in control of their actions, as well as a deep } \\
\text { sense of enjoyment. }\end{array}$ \\
\hline Self-determination theory [22] & $\begin{array}{l}\text { A positive state of emotion that reflects generalized feelings such as } \\
\text { pleasure, fun, and liking. }\end{array}$ \\
\hline $\begin{array}{l}\text { Self-efficacy theory and } \\
\text { achievement goal theory [23] }\end{array}$ & $\begin{array}{l}\text { A positive psychological state characterized by a sense of pleasure, fun, } \\
\text { and liking. Gender differences influence children's enjoyment. }\end{array}$ \\
\hline $\begin{array}{l}\text { Mood management theory and the } \\
\text { theory of planned behavior [29] }\end{array}$ & $\begin{array}{l}\text { Increases satisfaction of the gaming experience and is a strong predictor } \\
\text { of game enjoyment. A higher level of presence experienced was } \\
\text { positively correlated with game enjoyment and mood experience. }\end{array}$ \\
\hline
\end{tabular}




\begin{tabular}{|l|l|}
\hline $\begin{array}{l}\text { Cognitive load theory and } \\
\text { communication theory [32] }\end{array}$ & $\begin{array}{l}\text { Problem-solving, situated and social form of learning with prompt and } \\
\text { differentiated feedback. Enjoyment is primarily attributed to a game's } \\
\text { freedom. }\end{array}$ \\
\hline $\begin{array}{l}\text { Communication theory and self- } \\
\text { determination theory [37] }\end{array}$ & $\begin{array}{l}\text { The ground for emotion, attitude, action, and positive reaction towards } \\
\text { the satisfaction of intrinsic needs and the content of the games. }\end{array}$ \\
\hline $\begin{array}{l}\text { Self-determination theory, uses } \\
\text { and gratifications theory, } \\
\text { cognitive dissonance theory, flow } \\
\text { theory, and mood management } \\
\text { theory [41] }\end{array}$ & $\begin{array}{l}\text { Enjoyment is to the continued use and to be a predictor of intentions to } \\
\text { use utilitarian information technology. Perceived ease of use. } \\
\text { Interactivity appeared irrelevant. }\end{array}$ \\
\hline Flow theory [61] & $\begin{array}{l}\text { The relaxation that enables them to take things in more easily and } \\
\text { motivation which enables learners to put effort without displeasure. } \\
\text { Enjoyment is based on values, qualities, and rules of play or serious } \\
\text { frames. }\end{array}$ \\
\hline
\end{tabular}

Previous studies have differed widely on the definition of enjoyment as a pleasure response [57]. Enjoyment defined as a positive psychological state characterized by a sense of pleasure, fun, and liking while playing mobile games [23]. Enjoyment in gaming acts as the basis for various emotions, attitudes, actions, and positive reactions to the satisfaction of intrinsic needs and the content of the game [2,37]. Enjoyment is conceptualized as an attitude and suggested that the experience of enjoyment in response to gaming has behavioral, cognitive, and affective consequences [43].

There is also an increasing evidence showing how gender differences might influence children's enjoyment in games [32]. Girls appear to enjoy interactive dance games more than boys [23]. These gender differences might be the result of socialization, with boys feeling as though they are not able to appreciate interactive dance games, such as Dance Revolution, as much as they might enjoy traditional male sports or other competitive/combative activities. Therefore, enjoyment might be defined based on the type of game and gender. Previous studies have also shown that children who work together in small groups experience heightened levels of enjoyment [4]. Precisely, how much enjoyment players derive from a collaborative experience, however, is dependent upon their self-perceived skill level in comparison to others in the group.

According to classical game theorists, such as [30] and [7], enjoyment is largely attributable to the degree of freedom that a game affords the player. Such theories suggest that enjoyment is defined by the player's sense of being in control of their actions [11]. In short, players who feel that they are more in control when playing a game will generally enjoy more as compared to when they are playing games with rigid rules that restrict their freedoms. As such, [64] we conclude that enjoyment is based on values, qualities, and rules of play or serious frames.

Lyons also observes that feedback while playing games might affect enjoyment [39]. Given that the express purpose of game-based learning is for the player to learn from differentiated feedback on their performance promotes a more enjoyable learning experience [31]. Paradoxically, interactivity might be irrelevant, at least in so far as mobile gaming is concerned, with respondents preferring responsiveness in their gaming experience as the prime enjoyment [41].

The experience of failure in gaming also seems to be an important element that contributes to enjoyment $[33,43]$. The sense of being challenged while playing a game 
affects enjoyment, with the experience of failure motivating players to persist in trying to accomplish their goals [39]. The experience of enjoyment in the learning process causes the player to feel more relaxed, overcoming future challenges more easily and motivating them to apply greater effort [46]. Consequently, ease-of-use was by far the most significant construct contributing to player enjoyment, thus highlighting the importance of intuitive playability [41].

Moreover, the extant literature consistently correlates enjoyment with continued use [41], with [12] reporting that enjoyment is an important predictor of the intention to use utilitarian information technology. Other studies support a positive relationship between perceived enjoyment and attitudes to the use of technology. For example, [4] reported a significant correlation between user enjoyment and attitudes toward computer use. In sum, engagement with technology predicts usage enjoyment.

\subsection{Theoretical gaps}

The literature reviews summarized in Table 2 indicate that self-determination theory was used in five studies $(\mathrm{n}=5)$ looking to understand enjoyment in gaming. While most studies have defined enjoyment in terms of pleasure response, we argue that this conceptualization is inadequate. Tamborini has developed and validated a more expansive model of enjoyment, having investigated three basic needs according to self-determination theory: autonomy, competence, and relatedness [57]. Table 2 also shows that flow theory was used in four studies $(n=4)$. According to this theory, players of educational games may experience flow, which defines as being completely involved in an activity for its own sake, with every subsequent thought, movement, and action inevitably flowing from the previous one, like playing jazz [10]. Uses and gratifications theory (UGT) has also been used in three studies ( $n=3$ ). UGT essentially reverses the traditional psychological process of inquiry, taking an "outside-in" approach to identifying how motivation directs media use and how individuals respond to media "inside-out" [20]. For instance, Schramm [49] argue that more valuable insights might be gained from looking at how children use television as opposed to simply assuming that television does something to children.

\section{Discussion}

\subsection{Self-determination theory}

The potential to satisfy basic psychological needs related to competence, autonomy, and socialization are grounded in self-determination theory [20]. The enjoyment was derived from playing games that rely on three basic psychological needs: relatedness, autonomy, and competence [3]. These perspectives would suggest that playing games are internally motivated and directed. Westwood and Griffiths similarly found that games fell within several motivational categories, including those that motivate the players to socialize or to absorb themselves in the game's storyline [62]. This approach is consistent with the conclusions of other studies, that games - 
such as massively multiplayer online games (MMOs) - cater to players' basic need to socialize [19], and as such, children can meet their basic psychosocial developmental needs through gaming [19].

Having fun when gaming fulfills numerous needs. The competency-needs approach would suggest that it is necessary to have fun to achieve victories and to be good at something. Gaming also satisfies socialization needs when games provide players opportunities to connect socially with other players. Ferguson [20] argues that consistent with self-determination theory, children's motives for playing games can be categorized in terms of autonomy, competence, and social relatedness.

Self-determination theory alludes to three types of behavioral regulation: intrinsic motivation, extrinsic motivation, and motivation [23]. Intrinsic motivation refers to participation in activities for their own sake, enjoyment, and satisfaction. In contrast, extrinsic motivation is characterized by the player's pursuit of some goal or consequence (i.e. reward or avoiding punishment). Motivation, on the other hand, refers to the absence of an intention to act (i.e. the absence of motivation).

\subsection{Flow theory}

Csikszentmihalyi defines flow in terms of being completely involved in an activity for its own sake [10]. In terms of learning games, flow theory refers to the ability of the player to learn while playing and still manage to enjoy the experience [64]. Likewise, a player can feel different emotions, such as excitement, challenge, pleasure, and interest [26]. Past studies have shown that the flow state experienced while playing games positively affects the player's attitudes, behavior, and learning outcomes [55]. Therefore, we would argue that flow theory must be taken into account in the design of educational games. To this end, Sweetser and Wyeth developed the GameFlow model, based on flow theory [54]. The GameFlow model outlines seven criteria for identifying issues and reviewing games, as well as for understanding the effect of these issues on player enjoyment. These criteria include clear goals, challenge, concentration, control, feedback, player skills, and immersion [56].

As previously noted, quantifiably enjoyable games will challenge the player; however, it is important to distinguish between positive and negative challenges in games. Negative challenges in games are associated with problems, such as navigation difficulties or slow download times [36]. Positive challenges, on the other hand, can be recognized by the player's sense of flow and enjoyment, put more simply, by the player's perception of pleasurable feelings when the gameplay matches the player's skill level [4]. Hsu and Lu recognize the challenge, interactivity, and variety as important components of flow [29].

Primary reward systems, such as in-game stars or badges, are often used in gaming to maintain the player's motivation. Aabom argues that completing in-game challenges and story or quest-related goals is considered an important achievement that goes beyond the graphical rewards inside the game [1]. In the context of learning, Shernoff argues that flow experiences help the player to achieve their goals by enjoying the challenges in fun ways [53]. Therefore, as a learning behavior, 
enjoyment is the catalyst for other positive behaviors, such as persistence, learning, and motivation.

\subsection{Uses and gratifications theory}

Various studies have argued the value of applying UGT in games. Greenberg found that young children were particularly strong in fantasy motivations, while older children were more likely to be driven by competitive motives, with males generally being more motivated to play games than females [27]. Similarly, while [28] found that children were motivated by challenges in games, [38] found that children were instead more strongly subject to social motives. Chory advocate for the integration of the UGT approach with traditional psychological approaches to understanding media, with it being argued that a composite approach might yield valuable insights into the motivational and social context of children's use of media [8]. This approach stands in stark contrast to the traditional mechanistic media effects model, which focuses on the media itself. Consistent with this idea, Sherry proposed players have six motives to play games: diversion, fantasy, arousal, challenge, competition, and social interaction [27].

\subsection{Consolidating theories in game development}

Gamification has been used to increase the motivation of learners [6,61]. Gamifying learning, however, demands some recognition of which part of the game produces the most motivation. Gamification is usually concerned with the core aspects of the game, thus focusing primarily on issues of game mechanics, storyline, and the user experience [21]. Knowing this, we can design the core game based on various psychological theories aimed at increasing the player's motivation and level of enjoyment.

Self-determination theory, which aims to satisfy players' competence, autonomy and need for social relatedness, can be implemented through the careful selection of game design elements, such as game theme, non-fixed structures in the game flow, available missions or challenges, short-cycle of game time, cooperation or competition among the players, and the provision of feedback [61]. Flow theory would require that a game include challenging activities with clear goals and regular feedback [64]. As such, the player is required to exercise some skills in playing the game, with the outcome of the game being uncertain and based on the player's actions.

Malone promotes three game design specific attributes: challenge, fantasy, and curiosity [40]. As the player seeks to be challenged, the game must provide personally meaningful in-game goals, created through fantasy (e.g. storyline and characters) with which the player can empathize. Moreover, the game should build upon the player's existing body of knowledge to maintain their cognitive and sensory curiosity over time [40].

The elements suggested here can be incorporated into the design of health-based games, thus satisfying the player-learner's psychological needs. The various research 
articles contributing to this systematic review articulate a picture of enjoyment as a player response to having their needs or motives satisfied. The theories outlined here ultimately support one another concerning understanding human motivation [57]; indeed the UGT approach appears to fit well with self-determination theory.

\section{Limitation}

This review is limited by the number and rigor of the research articles identified to enjoyment in health-based games. Nonetheless, this systematic review is timely, highlighting several future research directions for promoting a more effective and comprehensive understanding of enjoyment in health-based games. Besides, this review incorporated data obtained via a structured search strategy inclusive of both quantitative and qualitative studies. Given the small number of participants in qualitative studies, questions might reasonably be asked concerning the generalizability of the findings of this review. Nonetheless, we would argue that data obtained from qualitative studies still represents a valuable contribution to this review, while also acknowledging possible issues with the validity and reliability of these studies.

\section{Implication}

The findings presented here can serve as a guide for future research directions attempting to the issue of enjoyment element or other elements in health-based games. Future research should focus on the identified gaps by the taxonomy of research gaps in this study [42]. We also want to encourage researchers to conduct experimental research to provide more conclusive data concerning the enjoyment element in healthbased games. The availability of such data would expand our understanding of the role of causality in gaming and provide for greater generalizability in the results. Besides, research efforts could also be undertaken to explore the best approaches for game-based learning in the teaching and learning process.

\section{Conclusion}

Playing games and having an enjoyable experience provides for a deeper learning that facilitates the process whereby the learner connects concepts, skills, and knowledge together in different situations and ultimately becomes more creative in their thinking and problem-solving. Despite the concept of enjoyment in gaming having been broadly defined, researchers have differed somewhat in their precise definition of the concept. The purpose of this study, therefore, was to expand the pool of knowledge concerning enjoyment in health-based gaming and to prompt discussion surrounding the definition of enjoyment in gaming. This systematic review of the research literature found various definitions of enjoyment in health-based games. Nevertheless, these studies would suggest that enjoyment is: 
a) A sensation of pleasure or positive feedback, and varies

b) Based on the type of games preferred by different genders

c) Based on the degree of freedom that they game allows

d) Based on prompt feedback

e) Based on game's complexity

f) Based on ease of use

g) Based on the degree by which the game engages with the play

h) Based on the computer user's attitudes

In conducting this review, we drew upon the taxonomy of research gaps [42] to better understand the subject under scrutiny; as such, the three most relevant theories to explain enjoyment in gaming include self-determination theory, flow theory, and UGT.

\section{Acknowledgements}

We are grateful for the funding given to us by the University Research Management Centre to conduct this research. This research was supported by the team members at the Innovative Learning Sciences Research Centre of Excellence (INNOVATE), Faculty of Educational Studies, Faculty of Medicine and Health Science, and the Faculty of Computer Science, Universiti Putra Malaysia (UPM) in collaboration with industry partners at Ingineworks Sdn. Bhd. Special thanks go to all who have contributed to this research. This systematic review is part of the "Putra Future Classroom-Ingeniworks Game Initiative: Community Building Through Health-Based Game for Future Learners and Young Malaysians" university-industry matching grant research project.

\section{References}

[1] Henrik Aabom. 2014. Exploring the Intrinsic Nature of Video Game Achievements. Aalborg University, Copenhagen, Denmark. Retrieved May 1, 2020 from http://projekter.aau.dk/projekter/files/201935913/Exploring_the_intrinsic_nature_of_video game_achievements.pdf

[2] Emrah Akman and ̃̃ Recep. 2019. Pupils' Opinions on an Educational Virtual Reality Game in Terms of Flow Experience. Int. J. Emerg. Technol. Learn. IJET 14, 15 (2019), 121-137. https://doi.org/10.3991/ijet.v14i15.10576

[3] Leonard A. Annetta. 2008. Video Games in Education: Why They Should Be Used and How They Are Being Used. Theory Pract. 47, 3 (July 2008), 229-239. https://doi.org/10. $\underline{1080 / 00405840802153940}$

[4] Youngkyun Baek and Achraf Touati. 2017. Exploring how individual traits influence enjoyment in a mobile learning game. Comput. Hum. Behav. 69, (April 2017), 347-357. https://doi.org/10.1016/j.chb.2016.12.053

[5] Johannes Breuer and Gary Bente. 2010. Why so serious? On the Relation of Serious Games and Learning. Eludamos J. Comput. Game Cult. 4, 1 (2010), 7-24. 
[6] Patrick Buckley and Elaine Doyle. 2016. Gamification and student motivation. Interact. Learn. Environ. 24, 6 (August 2016), 1162-1175. https://doi.org/10.1080/10494820.20 14.964263

[7] R. Caillois. 1961. Man, play, and games. Free Press, New York, NY.

[8] Rebecca M. Chory and Alan K. Goodboy. 2011. Is Basic Personality Related to Violent and Non-Violent Video Game Play and Preferences? Cyberpsychology Behav. Soc. Netw. 14, 4 (April 2011), 191-198. https://doi.org/10.1089/cyber.2010.0076

[9] Rik Crutzen, Jonathan van 't Riet, and Camille E. Short. 2016. Enjoyment: A Conceptual Exploration and Overview of Experimental Evidence in the Context of Games for Health. Games Health J. 5, 1 (2016), 15-20. https://doi.org/10.1089/g4h.2015.0059

[10] Mihaly Csikszentmihalyi. 1990. Flow: The Psychology of Optimal Experience. Harper \& Row, New York, NY.

[11] Mihaly Csikszentmihalyi. 2014. Toward a psychology of optimal experience. In Flow and the Foundations of Positive Psychology: The Collected Works of Mihaly Csikszentmihalyi. Springer, Dordrecht, Netherlands, 209-226. https://doi.org/10.1007/97894-017-9088-8_14

[12] Fred D. Davis, Richard P. Bagozzi, and Paul R. Warshaw. 1992. Extrinsic and Intrinsic Motivation to Use Computers in the Workplace1. J. Appl. Soc. Psychol. 22, 14 (July 1992), 1111-1132. https://doi.org/10.1111/j.1559-1816.1992.tb00945.x

[13] Sebastian Deterding, Dan Dixon, Rilla Khaled, and Lennart Nacke. 2011. From game design elements to gamefulness: defining "gamification." In Proceedings of the 15th International Academic MindTrek Conference on Envisioning Future Media Environments - MindTrek '11, ACM Press, Tampere, Finland, 9. https://doi.org/10.1145/2181037. 2181040, https://doi.org/10.4018/978-1-60960-495-0.ch006

[14] Damien Djaouti, Julian Alvarez, and Jean-Pierre Jessel. 2011. Classifying Serious Games: The G/P/S Model. In Handbook of Research on Improving Learning and Motivation through Educational Games: Multidisciplinary Approaches, Patrick Felicia (ed.). IGI Global, Hershey, PA, 118-136. https://doi.org/10.4018/978-1-60960-495-0

[15] David Drummond, Alice Hadchouel, and Antoine Tesnière. 2017. Serious games for health: three steps forwards. Adv. Simul. 2, 1 (December 2017), 3. https://doi.org/10.1186/ $\underline{\text { s41077-017-0036-3 }}$

[16] Kevin Durkin. 2010. Videogames and Young People with Developmental Disorders. Rev. Gen. Psychol. 14, 2 (June 2010), 122-140. https://doi.org/10.1037/a0019438

[17] Erik H. Erikson. 1977. Toys and Reasons: Stages in the Ritualization of Experience. Norton, New York, NY.

[18] Xiaowen Fang and Fan Zhao. 2010. Personality and enjoyment of computer game play. Comput. Ind. 61, 4 (2010), 342-349. https://doi.org/10.1016/j.compind.2009.12.005

[19] Hanif Fatta, Zulisman Maksom, and Mohd Hafiz Zakaria. 2019. Game-based Learning and Gamification: Searching for Definitions. Int. J. Simul. Syst. Sci. Technol. (February 2019). https://doi.org/10.5013/IJSSST.a.19.06.41

[20] Christopher J. Ferguson and Cheryl K. Olson. 2013. Friends, fun, frustration and fantasy: Child motivations for video game play. Motiv. Emot. 37, 1 (March 2013), 154-164. https ://doi.org/10.1007/s11031-012-9284-7

[21] A. Francisco-Aparicio, F. L. Gutíerrez-Vela, J. L. Isla-Montes, and J. L. G. Sanchez. 2013. Gamification: analysis and application. In New Trends in Interaction, Virtual Reality and Modeling, Victor M.R. Penichet, Antonio Peñalver and José A. Gallud (eds.). Springer London, London, England. https://doi.org/10.1007/978-1-4471-5445-7 
[22] Toru Fujimoto, Katsusuke Shigeta, and Yuki Fukuyama. 2016. The Research Trends in Game-Based Learning and Open Education. Educ. Technol. Res. Dev. 39, 1 (2016), 1523. https://doi.org/10.15077/etr.41038

[23] Zan Gao, Leslie Podlog, and Chaoqun Huang. 2013. Associations among children's situational motivation, physical activity participation, and enjoyment in an active dance video game. J. Sport Health Sci. 2, 2 (June 2013), 122-128. https://doi.org/10.1016/j.jshs. 2012.07.001

[24] Sarah Victoria Gentry, Andrea Gauthier, Beatrice L'Estrade Ehrstrom, David Wortley, Anneliese Lilienthal, Lorainne Tudor Car, Shoko Dauwels-Okutsu, Charoula K Nikolaou, Nabil Zary, James Campbell, and Josip Car. 2019. Serious Gaming and Gamification Education in Health Professions: Systematic Review. J. Med. Internet Res. 21, 3 (March 2019), e12994. https://doi.org/10.2196/12994

[25] Stefan Göbel, Sandro Hardy, Viktor Wendel, Florian Mehm, and Ralf Steinmetz. 2010. Serious games for health: personalized exergames. In Proceedings of the international conference on Multimedia - MM '10, ACM Press, Firenze, Italy, 1663. https://doi.org/ $10.1145 / 1873951.1874316$

[26] Isabela Granic, Adam Lobel, and Rutger CME Engels. 2014. The benefits of playing video games. Am. Psychol. 69, 1 (2014), 66. https://doi.org/10.1037/a0034857

[27] Bradley S. Greenberg, John Sherry, Kenneth Lachlan, Kristen Lucas, and Amanda Holmstrom. 2010. Orientations to Video Games Among Gender and Age Groups. Simul. Gaming 41, 2 (April 2010), 238-259. https://doi.org/10.1177/1046878108319930

[28] Karla R. Hamlen. 2011. Children's choices and strategies in video games. Comput. Hum. Behav. 27, 1 (January 2011), 532-539. https://doi.org/10.1016/j.chb.2010.10.001

[29] Chin-Lung Hsu and Hsi-Peng Lu. 2004. Why do people play on-line games? An extended TAM with social influences and flow experience. Inf. Manage. 41, 7 (2004), 853-868. https://doi.org/10.1016/j.im.2003.08.014

[30] J. Huizinga. 1955. Homo Ludens: A Study of the Play Element in Culture. Beacon Press, Boston, MA.

[31] Nina Iten and Dominik Petko. 2016. Learning with serious games: Is fun playing the game a predictor of learning success? Br. J. Educ. Technol. 47, 1 (January 2016), 151-163. https ://doi.org/10.1111/bjet.12226

[32] Katja Joronen, Anna Aikasalo, and Anne Suvitie. 2017. Nonphysical effects of exergames on child and adolescent well-being: a comprehensive systematic review. Scand. J. Caring Sci. 31, 3 (September 2017), 449-461. https://doi.org/10.1111/scs.12393

[33] J Juul. 2009. Fear of failing? The many meanings of difficulty in video games. In The video game theory reader 2, M. J. P. Wolf and B. Perron (eds.). Routledge, New York, NY, 237-252.

[34] Jalal Khouna, Lotfi Ajana, Ahmed Rhazal, and Abdelilah El Mokri. 2019. Are Educational Games Engaging and Motivating Moroccan Students to Learn Physics? An Experimental Study. Int. J. Emerg. Technol. Learn. 14, 16 (2019), 66-82. https://doi.org/10.3991/ijet.v14 i16.10641

[35] Christoph Klimmt, Tilo Hartmann, and Andreas Frey. 2007. Effectance and Control as Determinants of Video Game Enjoyment. Cyberpsychol. Behav. 10, 6 (December 2007), 845-848. https://doi.org/10.1089/cpb.2007.9942

[36] Marios Koufaris. 2002. Applying the technology acceptance model and flow theory to online consumer behavior. Inf. Syst. Res. 13, 2 (2002), 205-223. https://doi.org/10.1287/ isre.13.2.205.83 
[37] Seungmin Lee, Wonkyung Kim, Taiwoo Park, and Wei Peng. 2017. The Psychological Effects of Playing Exergames: A Systematic Review. Cyberpsychology Behav. Soc. Netw. 20, 9 (September 2017), 513-532. https://doi.org/10.1089/cyber.2017.0183

[38] A. Lenhart, J. Kahne, E. Middaugh, A. MacGill, C. Evans, and J. Mitak. 2008. Teens, video games and civics: Teens gaming experiences are diverse and include significant social interaction and civic engagement. Retrieved December 29, 2010 from http://www. pewinternet.org/PPF/r/263/report_display.asp

[39] Elizabeth J. Lyons. 2015. Cultivating Engagement and Enjoyment in Exergames Using Feedback, Challenge, and Rewards. Games Health J. 4, 1 (February 2015), 12-18. https:// doi.org/10.1089/g4h.2014.0072

[40] Thomas W. Malone. 1981. Toward a Theory of Intrinsically Motivating Instruction*. Cogn. Sci. 5, 4 (October 1981), 333-369. https://doi.org/10.1207/s15516709cog0504_2

[41] Jani Merikivi, Virpi Tuunainen, and Duyen Nguyen. 2017. What makes continued mobile gaming enjoyable? Comput. Hum. Behav. 68, (March 2017), 411-421. https://doi.org/10. 1016/j.chb.2016.11.070

[42] D. Anthony Miles. 2017. A taxonomy of research gaps: Identifying and defining the seven research gaps. Dr. Stud. Workshop Find. Res. Gaps - Res. Methods Strateg. August (2017), 1-10.

[43] Nurul Amelina Nasharuddin, Erzam Marlisah, Ahmad Iqmer Nashriq Mohd Nazan, Habibah Ab Jalil, Ismi Arif Ismail, Aini Marina Ma'arof, and Siti Suria Salim. 2019. Body Mass Index Awareness using Game-based Learning in Malaysia: Game Design and Initial User Experiences. In 2019 11th Computer Science and Electronic Engineering (CEEC), IEEE, 90-95. https://doi.org/10.1109/ceec47804.2019.8974325

[44] R. Oerter. 2000. Spiel als Lebensbewa“ ltigung. Einige Erkla“ r- ungsansa“ tze fu“ r Spielhandlungen [Play as coping with life. Some explanations for playful actions]. In Spielen und Fernsehen. U* ber die Zusammenha“nge von Spielund Medien in der Welt des Kindes [Playing and watching TV: On the connections between play and media in the child's world], S. Hoppe-Graff and R. Oerter (eds.). Juventa, Weinheim, Germany, 47-58.

[45] Kulothunkan Palasundram, Nurfadhlina Mohd Sharef, Nurul Nasharuddin, Khairul Kasmiran, and Azreen Azman. 2019. Sequence to sequence model performance for education chatbot. Int. J. Emerg. Technol. Learn. IJET 14, 24 (2019), 56-68. https://doi.o rg/10.3991/ijet.v14i24.12187

[46] Marc Prensky. 2002. The motivation of gameplay: The real twenty-first century learning revolution. Horiz. 10, 1 (March 2002), 5-11. https://doi.org/10.1108/10748120210431349

[47] Francesco Ricciardi and Lucio Tommaso De Paolis. 2014. A Comprehensive Review of Serious Games in Health Professions. Int. J. Comput. Games Technol. 2014, (2014), 1-11. https://doi.org/10.1155/2014/787968

[48] Ricardo Rosas, Miguel Nussbaum, Patricio Cumsille, Vladimir Marianov, Mónica Correa, Patricia Flores, Valeska Grau, Francisca Lagos, Ximena López, Verónica López, Patricio Rodriguez, and Marcela Salinas. 2003. Beyond Nintendo: design and assessment of educational video games for first and second grade students. Comput. Educ. 40, 1 (January 2003), 71-94. https://doi.org/10.1016/S0360-1315(02)00099-4

[49] W. Schramm, J. Lyle, and E. B. Parker. 1961. Television in the lives of our children. Stanford University Press, Redwood City, CA. https://doi.org/10.1126/science.133.3458.1 $\underline{066}$

[50] Daniel M. Shafer, Corey P. Carbonara, and Lucy Popova. 2011. Spatial Presence and Perceived Reality as Predictors of Motion-Based Video Game Enjoyment. Presence Teleoperators Virtual Environ. 20, 6 (December 2011), 591-619. https://doi.org/10.1162/P $\underline{\text { RES_a_00084 }}$ 
[51] D. W. Shaffer, R. Halverson, K. R. Squire, and J. P. Gee. 2005. Video games and the future of learning. University of Wisconsin-Madison, Wisconsin Center for Education Research, Madison, WI. https://doi.org/10.2172/7134495

[52] David J. Shernoff, Mihaly Csikszentmihalyi, Barbara Shneider, and Elisa Steele Shernoff. 2003. Student engagement in high school classrooms from the perspective of flow theory. Sch. Psychol. Q. 18, 2 (2003), 158-176. https://doi.org/10.1521/scpq.18.2.158.21860

[53] David J. Shernoff, Shaunti Knauth, and Eleni Makris. 2000. The quality of classroom experiences. In Becoming adult: How teenagers prepare for the world of work. Basic Books, New York, NY, 141-164.

[54] Katharina Sieberer-Nagler. 2015. Effective Classroom-Management \& Positive Teaching. Engl. Lang. Teach. 9, 1 (December 2015), 163. https://doi.org/10.5539/elt.v9n1p163

[55] Yongxia Xia Skadberg and James R. Kimmel. 2004. Visitors' flow experience while browsing a Web site: its measurement, contributing factors and consequences. Comput. Hum. Behav. 20, 3 (2004), 403-422. https://doi.org/10.1016/s0747-5632(03)00050-5

[56] Penelope Sweetser and Peta Wyeth. 2005. GameFlow: a model for evaluating player enjoyment in games. Comput. Entertain. CIE 3, 3 (2005), 3-3. https://doi.org/10.1145/10 77246.1077253

[57] Ron Tamborini, Nicholas David Bowman, Allison Eden, Matthew Grizzard, and Ashley Organ. 2010. Defining Media Enjoyment as the Satisfaction of Intrinsic Needs. J. Commun. 60, 4 (December 2010), 758-777. https://doi.org/10.1111/j.1460-2466.2010.015 $\underline{13 . x}$

[58] Achraf Touati and Youngkyun Baek. 2018. What Leads to Player's Enjoyment and Achievement in a Mobile Learning Game? J. Educ. Comput. Res. 56, 3 (2018), 344-368. https://doi.org/10.1177/0735633117713022

[59] Dimitrios Vlachopoulos and Agoritsa Makri. 2017. The effect of games and simulations on higher education: a systematic literature review. Int. J. Educ. Technol. High. Educ. 14, 1 (December 2017), 22. https://doi.org/10.1186/s41239-017-0062-1

[60] P. Vorderer, T. Hartmann, and C. Klimmt. 2019. Explaining the enjoyment of playing video games: The role of competition. In Proceedings of the second international conference on Entertainment computing, Carnegie Mellon University, Pittsburgh, PA, 1-9.

[61] Siaw-Chui Wee and Weng-Wai Choong. 2019. Gamification: Predicting the effectiveness of variety game design elements to intrinsically motivate users' energy conservation behaviour. J. Environ. Manage. 233, (March 2019), 97-106. https://doi.org/10.1016/j.jenv $\underline{\operatorname{man} .2018 .11 .127}$

[62] Dave Westwood and Mark D. Griffiths. 2010. The role of structural characteristics in video-game play motivation: A Q-methodology study. Cyberpsychology Behav. Soc. Netw. 13, 5 (2010), 581-585. https://doi.org/10.1089/cyber.2009.0361

[63] Y. H. Yang, W. Xu, H. Zhang, J. P. Zhang, and M. L. Xu. 2014. The Application of KINECT Motion Sensing Technology in Game-Oriented Study. Int. J. Emerg. Technol. Learn. 9, 2 (2014), 59-63. https://doi.org/10.3991/ijet.v9i2.3282

[64] Sabiha Yeni and Kursat Cagiltay. 2017. A heuristic evaluation to support the instructional and enjoyment aspects of a math game. Program 51, 4 (November 2017), 406-423. https:// doi.org/10.1108/PROG-07-2016-0050

[65] J. M. Yien, C. M. Hung, G. J. Hwang, and Y. C. Lin. 2011. A game-based learning approach to improving students' learning achievements in a nutrition course. Turk. Online J. Educ. Technol. 10, 2 (2011), 1-10. 


\section{Authors}

Assoc. Prof. Dr. Habibah Ab Jalil is an associate professor at Universiti Putra Malaysia (UPM). Apart from being an academician in Educational Technology, she was actively involved in multimedia production and training at the early stage of her career. At the international level, she is an Hon. Member of Governing Body for the IIMTS Ltd. UK. She has been involved in UNESCO projects since 2016 and the latest is on developing a policy brief on ICT-Driven Innovation in Higher Education in Asia-Pacific. At the national level, she was a member of MEIPTA and was involved in the development of various national policies including National policy on eLearning (DePAN), Malaysian MOOC Development Guideline, National Open Educational Resources and National Gamification. At the University level, she was a Coordinator and Associate Fellow of Teaching and Learning Innovation Division, Research Centre for Academic Development (CADe), Universiti Putra Malaysia. At present, she is the Coordinator of the Research Centre of Excellence for Innovative Learning Sciences (INNOVATE) and Putra Future Classroom (PFC), the first teaching and learning Research Centre of Excellence and smart classroom in UPM.

Dr. Nurul Amelina Nasharuddin is a senior lecturer at the Department of Multimedia, Faculty of Computer Science and Information Technology, Universiti Putra Malaysia, Malaysia. She received her Ph.D. from the Universiti Putra Malaysia, Malaysia in 2017. Her areas of study are on the natural language processing and textbased information retrieval. Her current research interests focus on teaching and learning technologies, user experience and usability studies, and multimedia-related computing.

Dr. Erzam Marlisah obtained his PhD from Universiti Putra Malaysia. Erzam's research area is on artificial intelligence and machine learning and their applications in particular reinforcement learning and evolutionary computing. His current research focuses on development of deep learning networks for decision making and rational planning. He is also interested in optimization tasks, reasoning in IOT and advanced reasoning techniques.

Dr. Ahmad Iqmer Nashriq Mohd Nazan is a senior lecturer in Public Health at the Faculty of Medicine and Health Sciences, Universiti Putra Malaysia (UPM). He received his public health training from University of Illinois at Urbana-Champaign (Master of Public Health) and University of Wisconsin-Milwaukee (PhD) in 2012 and 2017 respectively. His areas of expertise are on community and behavioral health promotion, social network and integration, educational statistics and measurement, as well as psychometrics. His current research interest focuses on innovative approaches to intervening socio-related health determinants among the poor.

Professor Dr. Ismi Arif Ismail is the deputy dean for research and graduate studies at the Faculty of Educational Studies, Universiti Putra Malaysia. He has been widely published, as author or co-author of a number of books, book chapters, monographs, proceedings, and scores of scholarly papers, abstracts and related materials in areas of extension and continuing education, innovative learning, leadership, youth development and human resource development. Dr. Ismi received a master's degree in Extension Education from UPM in 1999 and a doctorate in 
Continuing Education from the University of Warwick, United Kingdom in 2005. He is also a principal researcher at Innovative Learning Sciences Research Centre of Excellence, Institute for Social Science Studies, UPM and Institute for Youth Research (IYRES) at Ministry of Youth and Sports, Malaysia.

Dr. Aini Marina Ma'rof is currently a senior lecturer in Educational Psychology at the Faculty of Educational Studies, Universiti Putra Malaysia (UPM) where she teaches and conducts research in the area of Cognitive Sciences of Teaching and Learning. Her research areas include investigating moment-by-moment learning processes, measuring cognitive performance across the lifespan, analyzing interaction in collaborative learning environments, assessing development of student argumentation and reasoning skills, evaluating classroom interventions aimed at improving children's cognitive outcomes, and promoting emergent literacy skills among underserved populations. A previous research member of University of Illinois' Center for the Study of Reading, she is currently a research associate of UPM's Innovative Learning Sciences Research Centre of Excellence (INNOVATE) and Universiti Malaysia Kelantan's (UMK) Institute for Research and Poverty Management (InsPeK) and leads the establishment of TLx.Lab@INNOVATE which aims at spearheading transdisciplinary research on learning experiences in various settings.

Nur Ain Farhan Mohd Rusdi is a researcher at Innovative Learning Sciences Research Centre of Excellence (INNOVATE), Faculty of Educational Studies, Universiti Putra Malaysia.

Dr. Zeinab Zaremohzzabieh is a social researcher at the Faculty of Educational Studies, Universiti Putra Malaysia. Her research interests include youth development, social entrepreneurship, corporate social responsibility, and ICT for development.

Article submitted 2020-07-28. Resubmitted 2020-08-30. Final acceptance 2020-08-30. Final version published as submitted by the authors. 